\title{
Effect of Plastic Deformation on CCT-diagram of Multi-Phase Forging Steel
}

\author{
Anna Wojtacha', Marek Opiela ${ }^{1 *}$ \\ 1 Faculty of Mechanical Engineering, Silesian University of Technology, ul. Konarskiego 18A, 44-100 Gliwice, Poland \\ * Corresponding author's e-mail: marek.opiela@polsl.pl
}

\begin{abstract}
The paper presents the results of research on the influence of plastic deformation and cooling conditions on microstructure, hardness and a shape of CCT-diagram (Continuous Cooling Transformations) of newly developed multi-phase steel assigned for die forgings, combining high strength, crack resistance and fatigue strength. The diagrams of undeformed and plastically deformed supercooled austenite transformations of steel containing $0.175 \% \mathrm{C}, 1.87 \% \mathrm{Mn}, 1.0 \% \mathrm{Si}, 0.22 \% \mathrm{Mo}$ as well as Ti and $\mathrm{V}$ microadditions were determined. Dilatometric tests were performed using a Bahr 805 A/D dilatometer. Specimens were austenitized at the temperature of $1000{ }^{\circ} \mathrm{C}$ for $300 \mathrm{~s}$ and successively cooled to ambient temperature at selected rates ranging from $60{ }^{\circ} \mathrm{C} / \mathrm{s}$ to $0.1{ }^{\circ} \mathrm{C} / \mathrm{s}$. In order to determine the influence of plastic deformation on the shape of CCT-diagram, samples were deformed at the temperature of $1000{ }^{\circ} \mathrm{C}$ using a $50 \%$ degree of deformation, and then cooled in the same rate range (as the undeformed samples). The tests showed the following temperature results: $\mathrm{A}_{\mathrm{c} 3}=$ $960{ }^{\circ} \mathrm{C}, \mathrm{A}_{\mathrm{c} 1}=832{ }^{\circ} \mathrm{C}$ and a relatively low $\mathrm{M}_{\mathrm{S}}$ temperature equal to $330^{\circ} \mathrm{C}$. Plastic deformation of steel at the temperature of $1000^{\circ} \mathrm{C}$, prior to the beginning of phase transformations, leads to significant increase in the ferritic transformation range, shifting the temperature of its beginning higher temperatures in the whole range of cooling rates. It was also revealed that the specimens plastically deformed at the austenitizing temperature, exhibit higher hardness compared to the undeformed specimens. The elaborated CCT-diagrams of supercooled austenite transformations constitute the basis for correct development of the conditions of thermo-mechanical treatment of forgings from the tested steel.
\end{abstract}

Keywords: multi-phase steels, CCT-diagram, supercooled austenite, microstructure.

\section{INTRODUCTION}

One of the most dynamically developing groups of alloys with ferrous matrix is the group of multi-phase steels [1, 2], characterized by a combination of soft and hard structural constituents - the reason why their final mechanical properties are shaped similarly as in case of composite materials, where the matrix is one of the phases and strengthening material is the other [3]. In the past 15 years, intensive research has been observed, mainly in Japanese and German centers, concerning multiphase microstructure

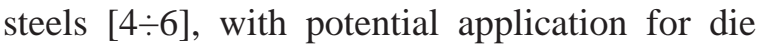
forgings with high strength and crack resistance. Such forgings are often operated under conditions of impact loads and require high strength in tough bending and/or torsional loads [7]. The forgings made of these steels should also be characterized by reduced weight and low production costs [8].

Technical and economic considerations determine that the majority of die forgings for the automotive industry, mining, agricultural and other machines is currently produced of ferritic-pearlitic microalloyed steels [9] or toughened steels [10]. Yet each group of these steels meets only selected properties specified above. Plastic deformation of ferritic-pearlitic steels with high rates and short duration of intervals for moving the forged part from one die impression to another one do not create convenient conditions for complete austenite static recrystallization and its subsequent grain 
refinement [11]. Ferritic-pearlitic steel forgings, air cooled from the temperature of plastic working finish, admittedly obtain high strength as a result of strong precipitation hardening and a high fraction of pearlite, but are also characterized by low crack resistance [12]. Increased mechanical properties, especially crack resistance, compared to the forgings with ferritic-pearlitic microstructures, can be obtained for low-alloyed toughening steels, forged with the method of thermo-mechanical processing. The main disadvantage of toughening steels is their high degree of alloying and many plastic and heat treatment operations necessary (process cost). No possibility to obtain desired functional properties of forgings is the result of carbides present in the steel, which may be the cause of fatigue cracks due to concentration of stresses [13].

The greatest potential for meeting quality requirements for forgings, combining high strength, crack resistance and fatigue strength, are multiphase steels with retained austenite $[14 \div 16]$. The presence of austenite, as the phase with highest plasticity among all structural constituents, enables simultaneous increase of strength and ductility of multi-phase steels. The absence of carbides in microstructure of multi-phase steels for forgings is achieved through increased concentration of $\mathrm{Si}$, which delays precipitation of cementite in bainitic ferrite [17].

The basis for the design of thermo-mechanical treatment, and in particular the temperaturetime profiles of several-step cooling of forgings from forging finish temperature, is the knowledge of the CCT diagrams of supercooled austenite transformations. Standard CCT diagrams are of limited use in the development of cooling conditions for forgings. However, diagrams of plastically deformed supercooled austenite transformations have the significant technical suitability. For example, Kawulok and Schindler [18] conducted the research on the influence of plastic deformation on the shape of CCT curves of steel containing $0.3 \% \mathrm{C}, 0.9 \% \mathrm{Mn}$ and $1 \%$ $\mathrm{Cr}$. The specimens after austenitizing at the temperature of $850{ }^{\circ} \mathrm{C}$, were deformed with a $30 \%$ deformation degree, before their controlled cooling in a rate range from $37{ }^{\circ} \mathrm{C} / \mathrm{s}$ to $0.16{ }^{\circ} \mathrm{C} / \mathrm{s}$. Plastic deformation resulted in a clear shift of phase transformations towards shorter times. The works $[19,20]$ present the results of research on the influence of plastic deformation on the shape of CCT curves of steel containing $0.2 \%$ C, $1.6 \%$ $\mathrm{Mn}, 0.9 \% \mathrm{Si}$ as well as $\mathrm{Nb}$ and Ti microadditions in concentrations of $0.035 \%$ and $0.023 \%$, respectively. Plastic deformation of austenite, before the beginning of phase transformations, led to enlargement of the ferritic bay area and a distinct increase in the temperature of the beginning of this transformation, regardless of the cooling rate. A slight decrease in the bainitic transformation start temperature was also observed. Similar issues, concerning the influence of plastic deformation on microstructure and the shape of CCT curves were presented in [21, 22].

Knowledge of multi-phase steels assigned for forgings is still minor. Optimal parameters of hot working and cooling profiles, ensuring effective combination of all the above-mentioned opposing material properties, at an acceptable cost of production, have not been developed yet. Therefore, the aim of the work is to investigate the influence of plastic deformation on a shape of the curves of supercooled austenite transformations in newly developed multi-phase steel with $\mathrm{Ti}$ and $\mathrm{V}$ microadditions, assigned for production of forgings with high functional properties, using the method of thermo-mechanical processing.

\section{MATERIALS AND METHODS}

The tests were carried out on steel containing $0.17 \%$ C, $1.87 \% \mathrm{Mn}, 1 \% \mathrm{Si}, 0.014 \% \mathrm{P}, 0.020 \% \mathrm{~S}$, $0.22 \% \mathrm{Mo}, 0.031 \%$ Ti and $0.022 \% \mathrm{~V}$, assigned for production of multi-phase die forgings, using the method of thermo-mechanical processing.

Ingots in a form of bars with diameter of 30 $\mathrm{mm}$ and length of $400 \mathrm{~mm}$ were melted in a VEM I20 type laboratory induction furnace. The presence of silicon in the steel in concentration of $1 \%$ prevents carbides to precipitate during bainitic transformation, when carbon diffuses into austenite and promotes its thermal stabilization. In order to strengthen and refine the microstructure, Ti and $\mathrm{V}$ microadditions were added to the steel.

Dilatometric tests were performed using a Bahr 805 A/D dilatometer, equipped with a LVDT type measuring head. Heating of specimens in the dilatometer was realized with the induction method, using a generator at a frequency of 250 $\mathrm{kHz}$. Heating and isothermal holding of samples at a given temperature was carried out in vacuum. Temperature deviations from an assigned value did not exceed $\pm 1^{\circ} \mathrm{C}$. The temperature measurement was done using S PtRh10-Pt type thermo element in the form of wire with a diameter of 0.1 
$\mathrm{mm}$. Dilatometric testing specimens, with diameter of $4 \mathrm{~mm}$ and length of $10 \mathrm{~mm}$, were heated at the rate of $3{ }^{\circ} \mathrm{C} / \mathrm{s}$ up to the temperature of 1000 ${ }^{\circ} \mathrm{C}$, held in the temperature for $300 \mathrm{~s}$ and successively cooled to ambient temperature at rates ranging from $60^{\circ} \mathrm{C} / \mathrm{s}$ to $0.1^{\circ} \mathrm{C} / \mathrm{s}$. In order to determine the influence of plastic deformation on the shape of CCT diagram, samples were deformed at the temperature of $1000^{\circ} \mathrm{C}$, using a $50 \%$ degree of deformation and strain rate of $1 \mathrm{~s}^{-1}$, and then cooled in the same rate range as the undeformed samples.

Examinations and analysis of the results were performed in accordance with the ASTM A103304 standard [23], using the technique consisting in putting a tangent against dilatation curve in the vicinity of the start and finish of phase transformation. Basing on the performed research, critical temperatures $\left(A_{c c}, A_{c 3}\right.$ and $\left.M_{s}\right)$ as well as ranges of phase transitions of supercooled austenite in the non-deformed state and after plastic deformation were determined. In order to identify microstructure of the products of supercooled austenite transformations, the samples were subjected to metallographic analysis using the Observer.Z1m light microscope and the SUPRA 25 scanning microscope after dilatometric tests. Specimens were etched in nital and - to reveal the presence of retained austenite - in Klemm's reagent, containing $50 \mathrm{ml}$ of $\mathrm{Na}_{2} \mathrm{~S}_{2} \mathrm{O}_{3}$ in $\mathrm{H}_{2} \mathrm{O}$ and $1 \mathrm{~g}$ of $\mathrm{K}_{2} \mathrm{~S}_{2} \mathrm{O}_{5}$. Microstructure was examined on transverse metallographic specimens using the bright-field observation technique. The HV10 hardness was measured using Vickers method with the load of $98 \mathrm{~N}$.

\section{RESULTS}

Conducted dilatometric tests allowed to determine the kinetics of supercooled austenite phase transformations in the newly developed steel. On the basis of the experiment, the $\mathrm{A}_{\mathrm{c} 1}$ and $\mathrm{A}_{\mathrm{c} 3}$ temperatures were determined, equal to $833^{\circ} \mathrm{C}$ and $960^{\circ} \mathrm{C}$, respectively. Dilatometric curves for selected cooling rates $\left(0.1^{\circ} \mathrm{C} / \mathrm{s}, 1^{\circ} \mathrm{C} / \mathrm{s}, 8^{\circ} \mathrm{C} / \mathrm{s}\right.$ and $60{ }^{\circ} \mathrm{C} / \mathrm{s}$ ), describing the relative change in length as a function of temperature, are shown in Fig. 1. Dilatometric curves (black lines), together with the blue lines that are tangent to them, make it possible to determine the start and finish temperatures of a phase transformation. In cases where the signal from the transformation is weak, the first derivative can be used to determine the temperature of the transformation start and finish (orange line in Fig. 1b). Data presented in Fig. 1a (for the cooling rate of $0.1^{\circ} \mathrm{C} / \mathrm{s}$ ) indicates that ferrite formation starts at the temperature of $810{ }^{\circ} \mathrm{C}$ and finishes at $743{ }^{\circ} \mathrm{C}$ during cooling. Precipitation of carbides occurs in the next stage. Bainite formation begins at the temperature of $726^{\circ} \mathrm{C}$. By analyzing the dilatometric curve for the cooling rate of $1^{\circ} \mathrm{C} / \mathrm{s}$, it can be noted that the signal coming from the transformation of ferrite is much stronger than that of bainite. This means that microstructure will be dominated by ferrite with a certain content of bainite. During cooling at the rate of $1{ }^{\circ} \mathrm{C} / \mathrm{s}$ (Fig. 1b) the transformation of ferrite is visible, and using the first derivative, bainite formation can also be identified. The signal is weak; hence ferrite will be the predominant phase.

During cooling at the rate of $8{ }^{\circ} \mathrm{C} / \mathrm{s}$ (Fig. 1c) the situation is analogous. For the highest cooling rate $\left(60^{\circ} \mathrm{C} / \mathrm{s}\right)$, formation of ferrite begins at the temperature of $607{ }^{\circ} \mathrm{C}$ and ends at $569{ }^{\circ} \mathrm{C}$ - Fig. 1d. Bainite formation begins at the same temperature. The results of performed research on the kinetics of transformations of undeformed supercooled austenite indicate that ferrite is the dominant phase in the examined steel, and in order to form harder structural constituents, very high cooling rates are necessary.

The CCT diagram of supercooled austenite transformations in the newly elaborated steel, containing $0.17 \% \mathrm{C}, 1.87 \% \mathrm{Mn}, 1 \% \mathrm{Si}, 0.22 \%$ Mo, $0.031 \% \mathrm{Ti}$ and $0.022 \% \mathrm{~V}$, as well as microstructures obtained after cooling the samples from the temperature of $1000{ }^{\circ} \mathrm{C}$, are shown in Fig. 2. According to the data presented in Fig. 2a, in the cooling rate range from $0.1^{\circ} \mathrm{C} / \mathrm{s}$ to 60 ${ }^{\circ} \mathrm{C} / \mathrm{s}$, microstructure of steel is composed mainly of ferrite and bainite. Along with an increase of cooling rate, the portion of bainite increases as well, while the portion of ferrite decreases. Regardless of the cooling rate, no pearlite was found in microstructure. This is due to high concentration of silicon, which delays formation of this structural constituent. Conducted measurements of hardness revealed that the sample cooled at the rate of $0.1^{\circ} \mathrm{C} / \mathrm{s}$ demonstrates the lowest hardness (144 HV10). At the lowest cooling rates, an increase in hardness is minor, which is only the result of microstructure refinement. Successively, the hardness increases along with an increase of the bainite portion. The highest hardness - equal approx. 222 HV10 - was observed for the sample cooled at the rate of $60{ }^{\circ} \mathrm{C} / \mathrm{s}$. 

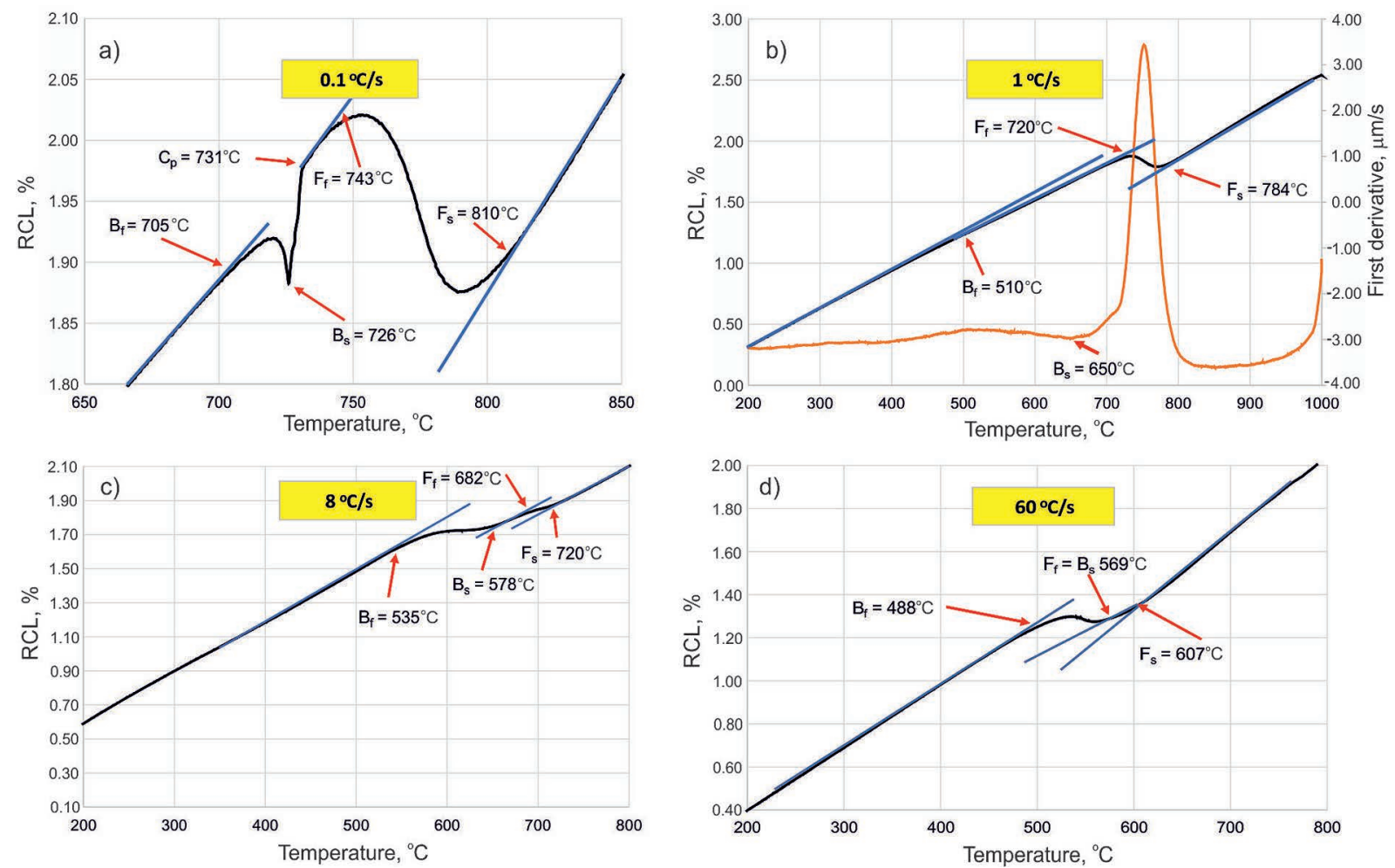

Fig. 1. Dilatometric curves for selected cooling rates: a) $0.1^{\circ} \mathrm{C} / \mathrm{s}$, b) $1{ }^{\circ} \mathrm{C} / \mathrm{s}$, c) $8{ }^{\circ} \mathrm{C} / \mathrm{s}$, d) $60^{\circ} \mathrm{C} / \mathrm{s}$
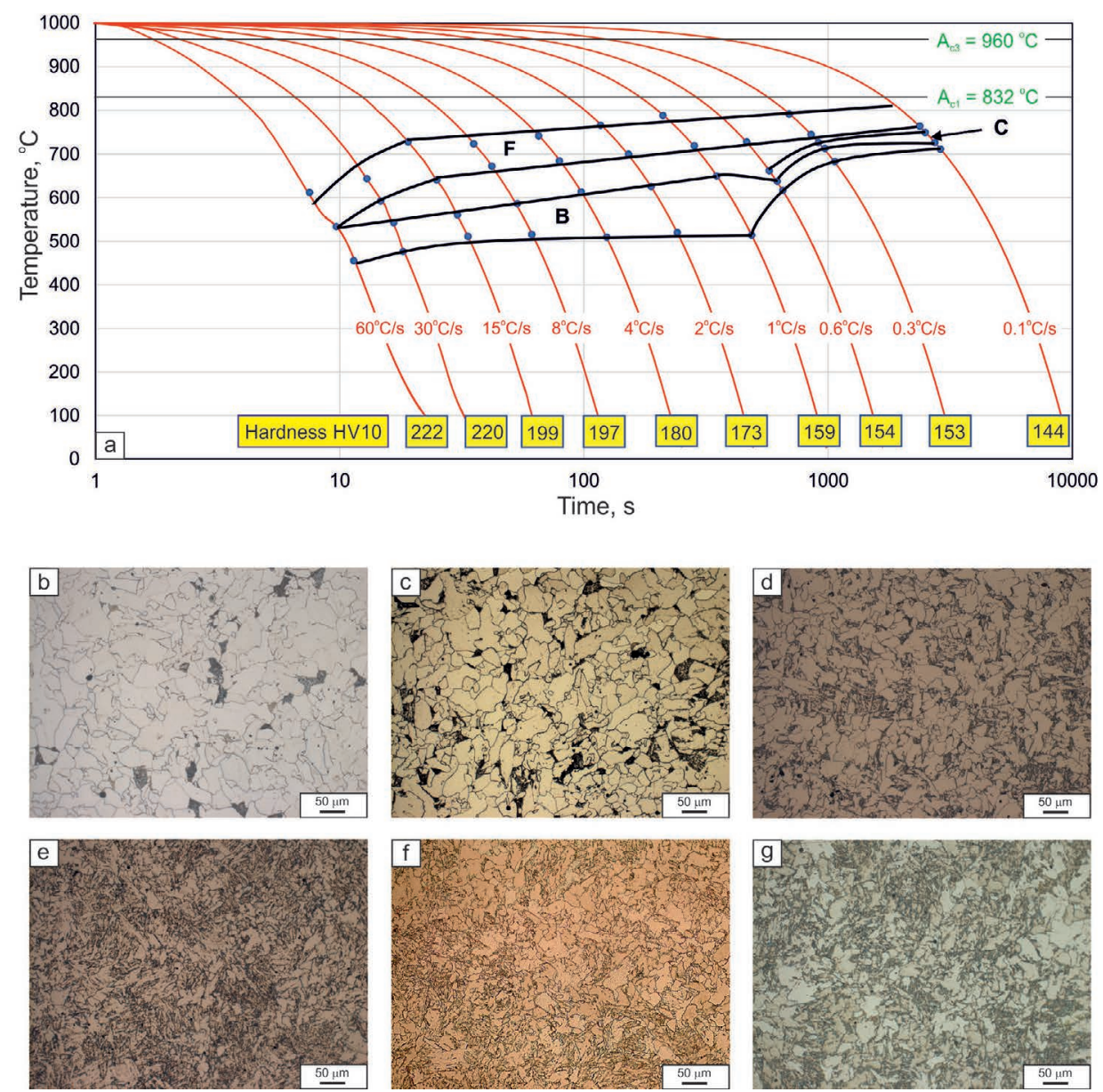

Fig. 2. Diagram of supercooled austenite transformations (a), with microstructures obtained after cooling at selected rates: b) $0.1{ }^{\circ} \mathrm{C} / \mathrm{s}$, c) $1{ }^{\circ} \mathrm{C} / \mathrm{s}$, d) $2{ }^{\circ} \mathrm{C} / \mathrm{s}$, e) $4{ }^{\circ} \mathrm{C} / \mathrm{s}$, f) $8{ }^{\circ} \mathrm{C} / \mathrm{s}$, g) $60^{\circ} \mathrm{C} / \mathrm{s}$ 

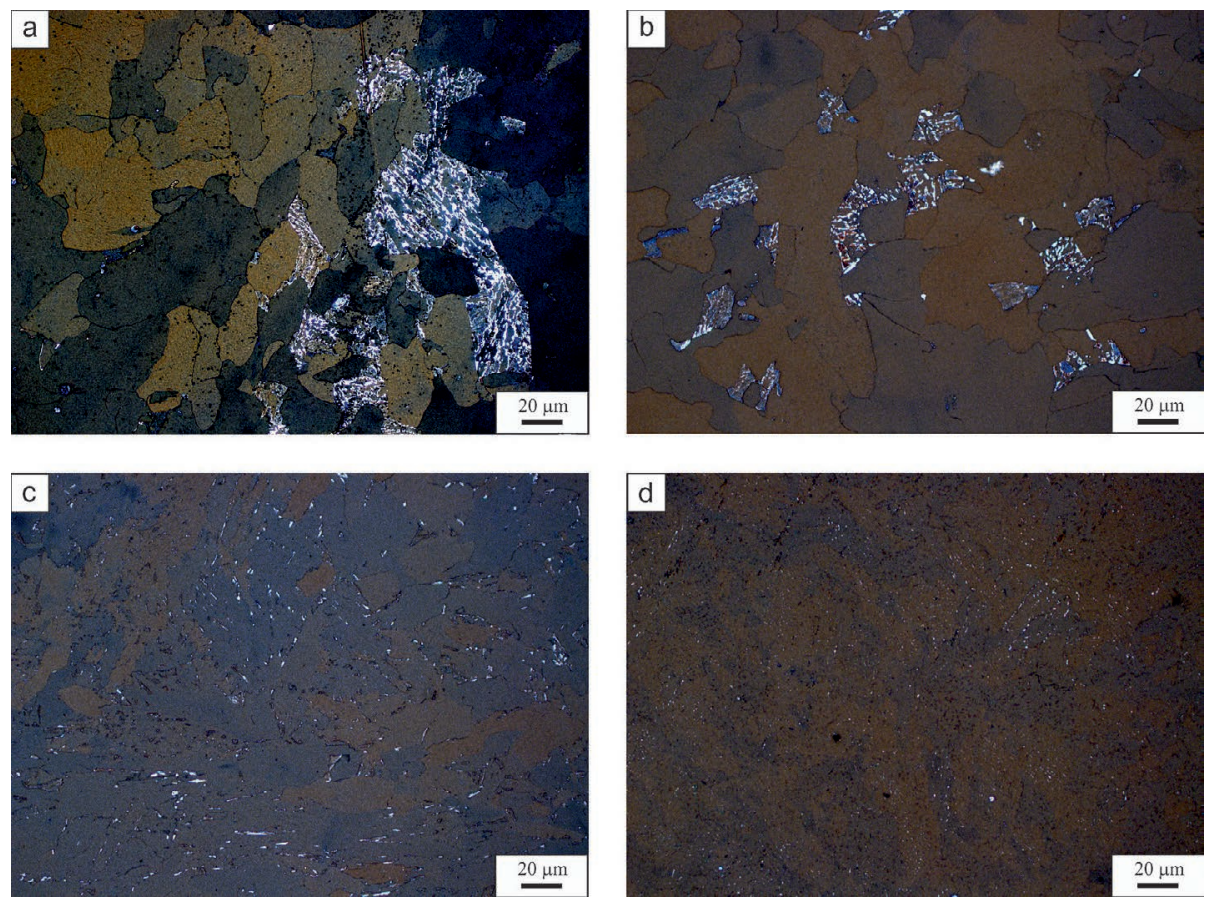

Fig. 3. Microstructures obtained after etching in Klemm's reagent at the cooling rates: a) $0.1^{\circ} \mathrm{C} / \mathrm{s}$, b) $1{ }^{\circ} \mathrm{C} / \mathrm{s}$, c) $8{ }^{\circ} \mathrm{C} / \mathrm{s}$, d) $60{ }^{\circ} \mathrm{C} / \mathrm{s}$

Microstructure of analyzed steel after etching in the Klemm's reagent, where individual structural constituents can be distinguished, is shown in Figure 3. The amount of retained austenite (phase visible in white) decreases with increasing cooling rate. The largest fraction of retained austenite can be observed during cooling at the rate of $0.1{ }^{\circ} \mathrm{C} / \mathrm{s}$, with this phase being present only locally in the bainite areas. A fraction of retained austenite is slightly lower in case of cooling the samples at the rate of $1^{\circ} \mathrm{C} / \mathrm{s}$ (Fig. 3b). In case of microstructure after cooling at the rate of $8{ }^{\circ} \mathrm{C} / \mathrm{s}$ (Fig. 3c), retained austenite is located at the boundaries of ferrite and bainite grains. The same applies to the variant of cooling at the rate of $60{ }^{\circ} \mathrm{C} / \mathrm{s}$. This is due to reduction of time necessary for diffusion of carbon into the austenite during formation of bainitic ferrite. Carbon takes time to penetrate the austenite, and high cooling rate shortens this time.

The CCT diagram of supercooled plastically deformed (at the temperature of $1000{ }^{\circ} \mathrm{C}$ ) austenite and microstructures of the samples cooled from this temperature at rates ranging from $0.1^{\circ} \mathrm{C} / \mathrm{s}$ to $60{ }^{\circ} \mathrm{C} / \mathrm{s}$ is shown in Figure 4. The tested steel has a relatively low $\mathrm{M}_{\mathrm{S}}$ temperature of $330^{\circ} \mathrm{C}$. In a cooling rate range from $0.1{ }^{\circ} \mathrm{C} / \mathrm{s}$ to $15^{\circ} \mathrm{C} / \mathrm{s}$, the microstructure of steel is ferritic-bainitic with a fraction of bainite increasing along with an increase in the cooling rate in this range. Applying the two highest cooling rates, i.e. $30^{\circ} \mathrm{C} / \mathrm{s}$ and
$60{ }^{\circ} \mathrm{C} / \mathrm{s}$, guarantees obtaining the microstructure composed of ferrite and some negligible amount of martensite. Plastic deformation of samples prior to their cooling resulted in refinement of the microstructure, when compared to non-deformed samples. The results of metallographic analysis are confirmed by the results of hardness measurements. Hardness of specimens, cooled directly after plastic deformation at the austenitizing temperature, increases from $149 \mathrm{HV} 10$ at the cooling rate of $0.1^{\circ} \mathrm{C} / \mathrm{s}$ to $228 \mathrm{HV} 10$ - at the cooling rate of $60^{\circ} \mathrm{C} / \mathrm{s}$. The increase in hardness in a cooling rate range from $0.1{ }^{\circ} \mathrm{C} / \mathrm{s}$ to $15^{\circ} \mathrm{C} / \mathrm{s}$ is the result of refinement of microstructure and increasing portion of bainite.

\section{DISCUSSION}

The results of the research on the kinetics of supercooled austenite transformations of steel show (Fig. 2) that for the cooling rate in a range from $0.1^{\circ} \mathrm{C} / \mathrm{s}$ to $1{ }^{\circ} \mathrm{C} / \mathrm{s}$, ferrite is the main phase in the microstructure with a small content of granular bainite (darker phase in the micrographs). The presence of granular bainite can be identified at higher magnification, as shown in Figure 5. According to Song et al. [24] formation of granular bainite is connected with the high temperature, low cooling rates $\left(0.02{ }^{\circ} \mathrm{C} / \mathrm{s} \div 0.4{ }^{\circ} \mathrm{C} / \mathrm{s}\right)$, high 

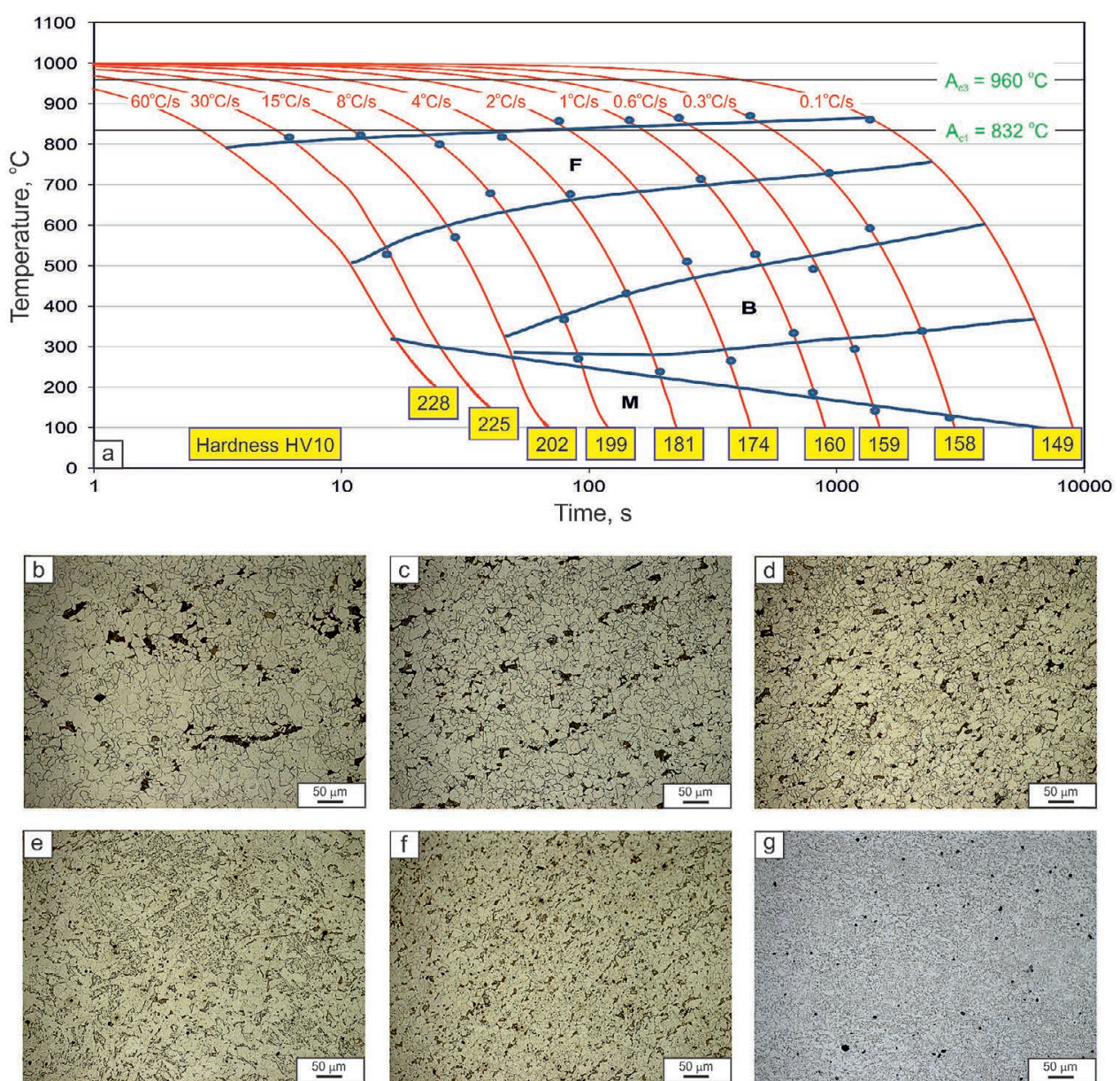

Fig. 4. Diagram of supercooled plastically deformed austenite transformations (a), with microstructures obtained after cooling at rates: b) $0.1{ }^{\circ} \mathrm{C} / \mathrm{s}$, c) $1{ }^{\circ} \mathrm{C} / \mathrm{s}$, d) $2{ }^{\circ} \mathrm{C} / \mathrm{s}$, e) $\left.4{ }^{\circ} \mathrm{C} / \mathrm{s}, \mathrm{f}\right) 8^{\circ} \mathrm{C} / \mathrm{s}$, g) $60{ }^{\circ} \mathrm{C} / \mathrm{s}$

carbon activity gradient and high carbon diffusion rates. This leads to the presence of carbon-depleted areas, which are successively carbon-enriched. During cooling, it results in formation of larger ferrite grains, with carbon-rich austenite islands between them. These islands eventually decompose into ferrite and cementite with a small fraction of retained austenite. The same conclusion was reached by Qiao et al. [25] in a high-strength steel. They noticed that during transformation of austenite into bainite, two different types of bainite can be formed. One is the result of formation and equiaxial growth of ferrite from low-carbon areas of austenite (granular bainite). The other is formed parallel to each other in several preferred orientations, which leads to formation of matrix by joining ferritic laths (bainitic ferrite). The investigated steel contains the first type of bainite mentioned. This is consistent with the results of dilatometric tests, on the basis of which it is possible to observe the development of ferritic matrix, precipitation of carbides and formation of bainite. Moreover, Zhao et al. [26] reported that granular bainite is formed at relatively high temperatures. This explains why formation of granular bainite, in case of examined steel, took place at the temperature of approx. $700^{\circ} \mathrm{C}$. At cooling rates of $8{ }^{\circ} \mathrm{C} / \mathrm{s}$ and faster, bainite dominates in the microstructure. Moreover, an increase in the cooling rate favours grain refinement.

The results of research with the use of scanning electron microscopy are presented in Figure 5. As previously shown, microstructure consists mainly of ferrite. However, the presence of a local mixture of different phases between ferrite grains is also visible at the cooling rates of $0.1^{\circ} \mathrm{C} / \mathrm{s}$ and $1{ }^{\circ} \mathrm{C} / \mathrm{s}$. Figures $5 \mathrm{a}$ and $5 \mathrm{~b}$ show a mixture of granular bainite with a very small amount of martensiticaustenitic islands and retained austenite. Stabilization of retained austenite is the result of its enrichment with carbon during formation of bainite. High Si content prevents formation of cementite during bainitic transformation. According to Kozeschnik and Bhadeshia [27], silicon limits the free change of transformation energy, which significantly delays precipitation of cementite in steel. Similar results were obtained by Suzuki et 

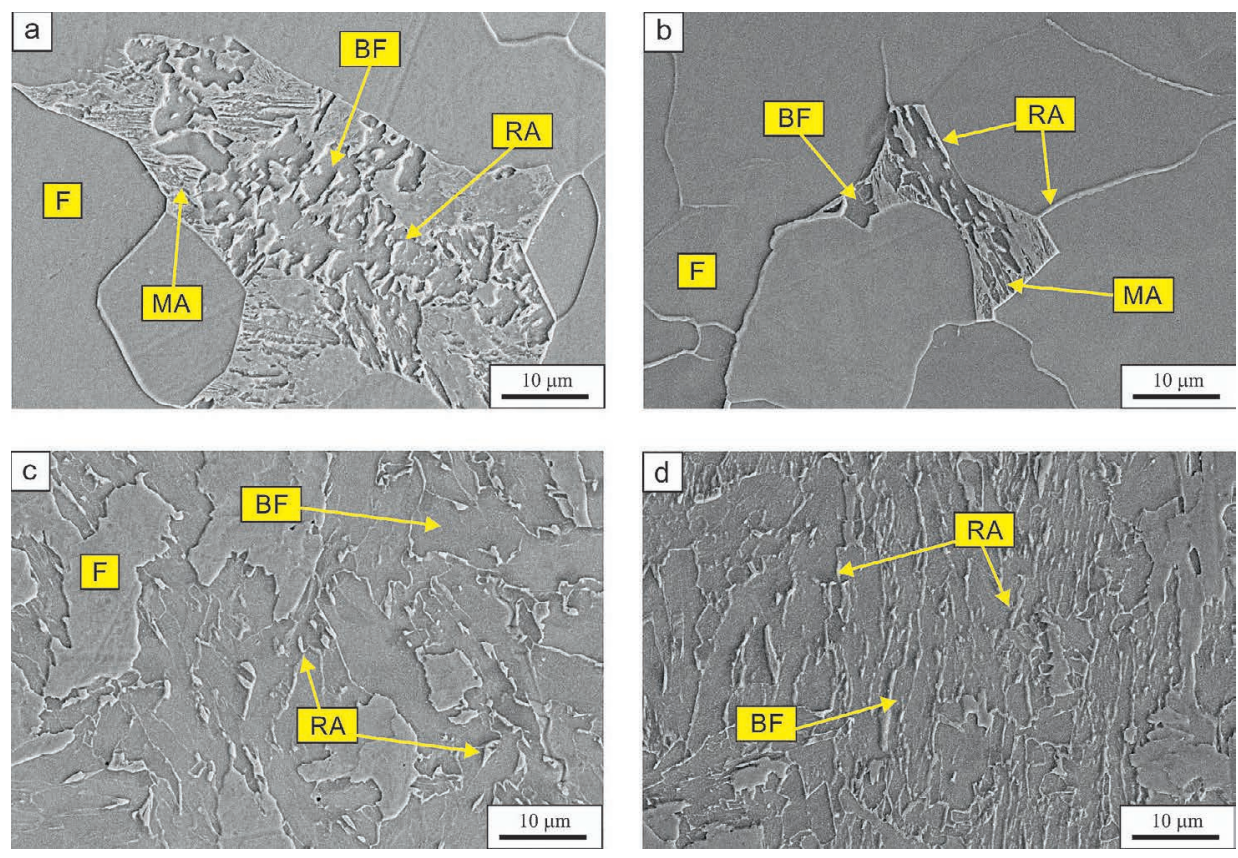

Fig. 5. SEM microstructures obtained after cooling of samples at rates: a) $0.1^{\circ} \mathrm{C} / \mathrm{s}$, b) $1{ }^{\circ} \mathrm{C} / \mathrm{s}$, c) $8{ }^{\circ} \mathrm{C} / \mathrm{s}$, d) $60^{\circ} \mathrm{C} / \mathrm{s}$; F - ferrite, $\mathrm{BF}$ - bainitic ferrite, MA - martensitic-austenitic island, RA - retained austenite

al. [28], Chen et al. [29] and Caballero et al. [30]. At a higher cooling rate $\left(1{ }^{\circ} \mathrm{C} / \mathrm{s}\right)$, granular bainite is more uniformly distributed. Microstructure of steel during cooling at the rate of $8{ }^{\circ} \mathrm{C} / \mathrm{s}$ (Fig. 5c) and $60^{\circ} \mathrm{C} / \mathrm{s}$ (Fig. 5d) consists of ferrite, bainitic ferrite and a small portion of retained austenite at grain boundaries and between bainitic laths. At the cooling rate of $8{ }^{\circ} \mathrm{C} / \mathrm{s}$, bainite takes on a more blocky shape, which can also be referred to as granular bainite.

SEM microstructures of specimens subjected to plastic deformation before the transformation and successive cooling with a rate in the range from $0.1{ }^{\circ} \mathrm{C} / \mathrm{s}$ to $60{ }^{\circ} \mathrm{C} / \mathrm{s}$, are shown in Figure 6 . As presented, plastic deformation caused a distinct refinement of microstructure. Similarly as in the case of non-deformed samples, the microstructure consists mainly of ferrite and locally granular bainite, martensitic-austenitic islands and retained austenite, located mainly at grain boundaries and between laths of bainite.

Analyzing the CCT diagram of the supercooled plastically deformed austenite transformations (Fig. 4a), a clear shift of the ferritic transformation bay to the left can be observed, i.e. towards shorter time compared to the limits of this phase transformation of undeformed supercooled austenite (Fig. 2a). Moreover, it was found that plastic deformation of samples prior to their controlled cooling causes significant increase of the $\gamma \rightarrow \alpha$ transformation start temperature. For example, the temperature of the beginning of the $\gamma \rightarrow \alpha$ transformation for extreme cooling rates, i.e. $0.1^{\circ} \mathrm{C} / \mathrm{s}$ and $60^{\circ} \mathrm{C} / \mathrm{s}$, is equal to $810^{\circ} \mathrm{C}$ and $607^{\circ} \mathrm{C}$, while the transformation start temperatures, after preceding plastic deformation of samples for indicated cooling rates, are equal to $843{ }^{\circ} \mathrm{C}$ and $799{ }^{\circ} \mathrm{C}$. The difference concerning the temperature of the beginning of the $\gamma \rightarrow \alpha$ transformation for both cases, increases along with the increase of the cooling rate. Plastic deformation of specimens before their controlled cooling resulted also in the distinct expansion of the ferritic transformation bay and significant reduction in bainitic transformation start temperature. Similar effects were obtained in the works [19, 20], the subject of which were studies of the impact of plastic deformation on the CCT diagrams of supercooled austenite transformations in a multiphase steel with a similar chemical composition. After austenitizing at the temperature of $1100{ }^{\circ} \mathrm{C}$ for $300 \mathrm{~s}$, specimens were plastically deformed at the same rate and with the same degree of deformation as the analyzed steel. Plastic deformation of samples with a $50 \%$ degree of deformation and a strain rate of $1 \mathrm{~s}^{-1}$ caused a shift of the ferritic transformation to shorter time. Moreover, an increase of the area of ferritic transformation was demonstrated along with an increase in the $\gamma \rightarrow \alpha$ transformation start temperature. The similar research results were obtained in a Nb-Timicroalloyed steel [31].

Plastic deformation of austenite caused the increase of dislocation density and the 

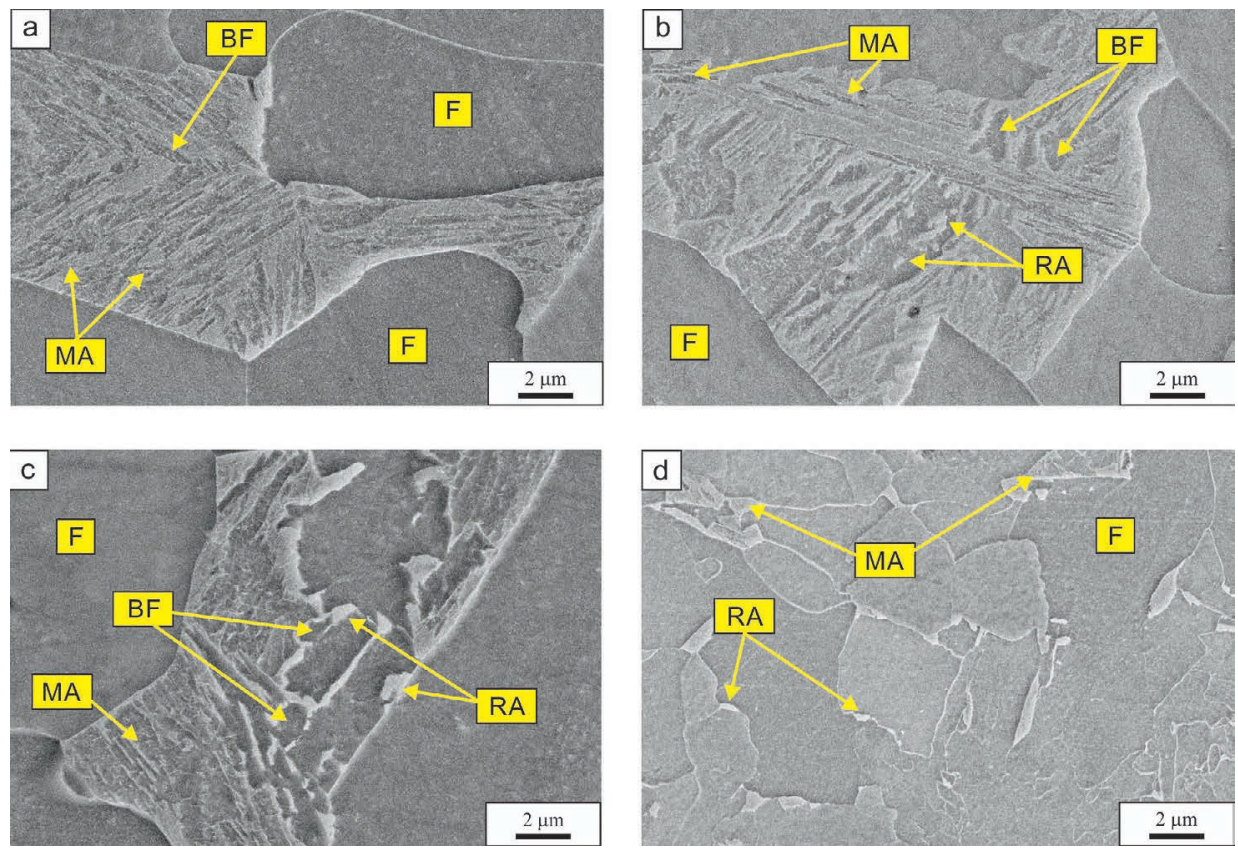

Fig. 6. SEM microstructures obtained after plastic deformation and subsequent cooling of samples at rates: a) $0.1{ }^{\circ} \mathrm{C} / \mathrm{s}$, b) $1{ }^{\circ} \mathrm{C} / \mathrm{s}$, c) $8{ }^{\circ} \mathrm{C} / \mathrm{s}$, d) $60^{\circ} \mathrm{C} / \mathrm{s}$; F - ferrite, BF

- bainitic ferrite, $\mathrm{MA}$ - martensitic-austenitic island, RA - retained austenite

strengthening as a result of grain refinement, which was confirmed by higher hardness of samples cooled at the same rate, compared to the hardness of non-deformed samples.

\section{CONCLUSIONS}

Performed tests allowed evaluating the influence of plastic deformation and cooling rates on the shape of CCT diagram of supercooled austenite transformations of newly elaborated steel. Plastic deformation of samples at the temperature of $1000^{\circ} \mathrm{C}$, prior to their controlled cooling in the rate range from $0.1{ }^{\circ} \mathrm{C} / \mathrm{s}$ to $60^{\circ} \mathrm{C} / \mathrm{s}$, results in:

- distinct shift of the $\gamma \rightarrow \alpha$ transformation to shorter time,

- enlargement of the ferritic transformation bay area,

- increase of the $\gamma \rightarrow \alpha$ transformation start temperature, regardless of applied cooling rate,

- decrease of the bainitic transformation start temperature,

- refinement of microstructure and an increase of hardness.

The CCT diagram shape of supercooled austenite transformations fully predisposes the examined Ti-V-microalloyed steel for production of multiphase forgings and will be helpful in the development of thermo-mechanical processing conditions.

\section{REFERENCES}

1. Escobar J.D., Poplawsky J.D., Faria G.A., Rodriguez J., Oliveira J.P., Salvador C.A.F., Mei P.R., Babu S.S., Ramirez A.J. Compositional analysis on the reverted austenite and tempered martensite in a Ti-stabilized supermartensitic stainless steel: segregation, partitioning and carbide precipitation. Materials. 2018;140:95-105.

2. Calderón I.D., Calvillo R., Lara A. Effect of microstructure on fatigue behavior of advanced high strength steels produced by quenching and partitioning and the role of retained austenite. Materials Science \& Engineering A. 2015;641:215-224.

3. Conde F.F., Escobar J.D., Oliveira J.P., Jardini A.L., Bose Filho W.W., Avila J.A. Austenite reversion kinetics and stability during tempering of an additively manufactured maraging 300 steel. Additive Manufacturing. 2019;29:1-8.

4. Sugimoto K., Hojo T., Kobayashi J. Critical assessment of TRIP-aided bainitic ferrite steels. Materials Science and Technology. 2017;33(17):2005-2009.

5. Sugimoto K., Hojo T., Mizuno Y. Torsional fatigue strength of newly developed case hardening TRIPaided steel. Metals. 2017;7(375):1-13.

6. Keul C., Wirths V., Bleck W. New bainitic steel for forgings. Archives of Civil and Mechanical Engineering. 2012;12:119-125.

7. Zhao P., Cheng C., Gao G., Hiu W., Misra R.D.K., Bai B., Weng Y. The potential significance of microalloying with niobium in governing very high 
cycle fatigue behavior of bainite/martensite multiphase steels. Materials Science \& Engineering A. 2016;650:438-444.

8. Guhui G., Baoxiang Z., Cheng C., Ping Z. Very high cycle fatigue behaviors of bainite/martensite multiphase steel treated by quenching-partitioning-tempering process. International Journal of Fatigue. 2016;92:203-210.

9. Kuziak R., Bołd T., Cheng Y. Microstructure control of ferrite-pearlite high strength low alloy steels utilizing microalloying additions. Journal of Materials Processing Technology. 1995;53:255-262.

10. Adamczyk J., Opiela M. Engineering of forged products of microlloyed constructional steels. Journal of Achievements in Materials and Manufacturing Engineering. 2006;15:153-158.

11. Adamczyk J., Kalinowska-Ozgowicz E., Ozgowicz W., Wusatowski R. Interaction of carbonitrides $\mathrm{V}(\mathrm{C}, \mathrm{N})$ undissolved in austenite on the structure and mechanical properties of microalloyed $\mathrm{V}-\mathrm{N}$ steels. Journal of Materials Processing Technology. 1995;54:23-32.

12. Skubisz P., Adrian H., Sińczak J. Controlled cooling of drop forged microalloyed-steel automotive crankshaft. Archives of Metallurgy and Materials. 2011;56:93-107.

13. Kuziak R., Pidvysotskyy V., Węglarczyk S., Pietrzyk M. Bainitic steels as alternative for conventional carbon-manganese steels in manufacturing of fasteners - simulation of production chain. Computer Methods and Materials Science. 2011;11:443-462.

14. Gramlich A., Emmrich R., Bleck W. Austenite reversion tempering-annealing of 4 wt.\% manganese steels for automotive forging application. Metals. 2019;9(575):1-10.

15. Li Q., Huang X., Huang W. Strain hardening behavior and deformation characteristic of multiphase microstructure in a medium-carbon quenching and partitioning bainitic steel. Materials Science \& Engineering A. 2017;707:199-206.

16. Siodlak D., Lotter U., Kawalla R., Schwich V. Modelling of the mechanical properties of low alloyed multiphase steels with retained austenite taking into account strain-induced transformation. Steel Research International. 2008;79:776-783.

17. Grajcar A., Zalecki W., Burian W., Kozłowska A. Phase equilibrium and austenite decomposition in advanced high-strength medium-Mn bainitic steels. Metals. 2016;6(10):1-14.

18. Kawulok R., Schindler I., Kawulok P., Rusz P., Opéla P., Solowski S., Čmiel K.M. Effect of deformation on the continuous cooling transforma- tion (CCT) diagram of steel 32CrB4. Metalurgija. 2015;53(3): 473-476.

19. Grajcar A. \& Opiela M. Diagrams of supercooled austenite transformations of low-carbon and medium-carbon TRIP-steels. Archives of Materials Science and Engineering. 2008;32:13-16.

20. Grajcar A., \& Opiela M. Influence of plastic deformation on CCT-diagrams of low-carbon and medium-carbon TRIP-steels. Journal of Achievements in Materials and Manufacturing Engineering. 2008;29(1):71-78.

21. Bräutigam-Matus K., Altiminaro G., Salinas A., Flores A., Goodwins F. Experimental determination of continuous cooling transformation (CCT) diagrams for dual-phase steels from the intercritical temperature range. Metals. 2018;8(9):1-16.

22. Grajcar A., Kwasny W., Zalecki W. Microstructure-property relationships in TRIP aided medium-C bainitic steel with lamellar retained austenite. Materials Science and Technology. 2015;31(7):781-794.

23. ASTM A1033-04. In standard practice for quantitative measurement and reporting of hypoeutectoid carbon and low-alloy steel phase transformations. ASTM International: West Conshohocken, USA.

24. Song W., Lei M., Wan M., Huang C. Continuous cooling transformation behavior and bainite transformation kinetic of 23CrNi3Mo carburized steel. Metals. 2021;11(1):1-12.

25. Qiao Z.X., Liu Y.C., Yu L.M., Gao Z.M. Formation mechanism of granular bainite in a 30CRNi3MoV steel. Journal of Alloys Compounds. 2009;475(1-2):560-564.

26. Zhao H. \& Palmiere E.J. Influence of cooling rate on the grain-refining effect of austenite deformation in a HSLA steel. Materials Characterization. 2019;158:1-12.

27. Kozeschnik E., Bhadeshia H.K.D.H. Influence of silicon on cementite precipitation in steels. Materials Science and Technology. 2008;24(3):343-347.

28. Suzuki T., Ono Y., Miyamoto G., Furuhara T. Effects of $\mathrm{Si}$ and $\mathrm{Cr}$ on bainite microstructure of medium carbon steels. ISIJ International. 2010;50:1476-1482.

29. Chen Z., Gu J., Ham L. Bainite transformation characteristics of high-Si hypereutectoid bearing steel. Metallography, Microstructure and Analysis. 2018;7:3-10.

30. Caballero F.G., Bhadeshia H.K.D.H. Very strong bainite. Current Opinion in Solid State \& Materials Science. 2004;8:251-257.

31. Grajcar A., Morawiec M., Zalecki W. Austenite decomposition and precipitation behavior of plastically deformed low-Si microalloyed steel. Metals. 2018;8:1028. 